\title{
Chapter 6. Developing Learning- Centered Approaches across the Discipline: Implementing Curated ePortfolios in Information Technology and International Studies
}

\author{
Kathryn Coleman \\ University of Melbourne \\ Sophie McKenzie \\ DEAKIN University \\ Cai Wilkinson \\ DEAKIN UNIVERSITY
}

Higher education has seen significant changes in the focus of digital learning, teaching, and assessment in the last decade. The shift has moved to focus on assessment as learning, rather than of learning, and to a more evidence-based understanding of assessment. In response to this shift, Deakin University recently engaged in a university-wide process of course/program ${ }^{1}$ enhancement to offer anywhere, anytime learning to its learners. Deakin University's teaching and learning strategic goal presented in LIVE the future ${ }^{2}$ (Oliver, 2015) tackled "course enhancement" by implementing an underpinning curriculum model and assurance of learning through aligned learning outcomes and evidence-based assessment. Course enhancement was a faculty-wide program of evaluation, graduate attribute alignment, innovative digital learning design, and academic development. Under the leadership of Professor Beverley Oliver, Deputy Vice-Chancellor (Education), and the Deakin Learning Futures team, this high-quality course enhancement was an innovative and groundbreaking university-wide approach to learning design, student experience, and higher education teaching. It allowed for a broad and wide-reaching program of deep professional learning for faculty to co-design and co-develop future focused, authentic, and digital learning, teaching and assessment programs. Commencing in late 2012, it was an initiative of Deakin's LIVE the Future: Agenda 2020 and led by a set of overarching and

1. In the Australian context, a course is a program of study leading to a degree and is made up of a number of units (courses), normally 24 in a three-year undergraduate degree.

2. LIVE is an acronym for Deakin's curriculum framework. 
guiding principles. Course enhancement was "designed to ensure that courses are enhanced to enable graduates to be highly employable through unit and course experiences that are personal, relevant and engaging wherever learning takes place-on campus, in the cloud, in industry settings" (Course Enhancement Guidelines, 2015). LIVE the future stands for:

- Learning: Offer brilliant education where you are and where you want to go.

- Ideas: Make a difference through world-class innovation and research.

- Value: Strengthen our communities, enable our partners and enhance our enterprise.

- Experience: Delight our students, our alumni, our staff and our friends. (2016)

Course enhancement included scaffolding to facilitate the university's strategic goals. That same scaffolding also supported learners' efforts to show how their portfolios evidenced skills, experience, and knowledge that aligned to employer requirements.

The course enhancement process focused on key employability skills, or graduate learning outcomes, and how best to integrate these within courses and degree programs as learning outcomes (O’Brien \& Oliver, 2013). Graduate learning outcomes are designed to align across knowledge, skills, and experiences that have been applied and demonstrated through assessment across a course or program and show what has been achieved to a range of audiences-including the learner. With a shift in both the language of assessment and an understanding of how learners demonstrate their learning, ideas, knowledge, experiences, and skills within programs for themselves and potential employers, ePortfolios emerged as a pedagogical tool for learning and assessment (see Sanborn \& Ramírez, this collection). The construction and curation of learning evidence helps a student develop and sustain an authentic professional identity. This digital learning environment, along with opportunities for cloud learning ${ }^{3}$ at Deakin University, provided us the space to design and develop ePortfolios for learning and assessment that presented a student's collected knowledge focused within a framework for employability (see Polly et al., this collection). The selection of the platforms allowed not only for the aggregation of artifacts in a wide range of formats, but also for the embedding of ongoing reflection through curation based on self-review, peer review, and peer assessment. This selection of platforms was an important factor to enable the sharing of the ePortfolio via social networks that related to the needs of the discipline in authentic contexts.

Deakin is a multi-campus university in Melbourne, Australia and uses the DesirezLearn Brightspace platform and embedded ePortfolio. The template of

3. Cloud learning denotes an opportunity to teach, learn, and assess digitally, using digital pedagogies. 
the Learning Management Space (LMS) is customized to suit the needs of the Deakin teaching and learning community and is called CloudDeakin. A small number of programs at Deakin have been using ePortfolios, for a range of purposes, more typically at the class and/or course level for small learning experiences. Through the course enhancement process, a growing number of programs have begun to adopt ePortfolios across their curriculum for evidencing learning to a range of stakeholders. This evidence of learning approach demonstrates the value of the ePortfolio as a pedagogical tool to support institutional change for learning-centered approaches.

The chapter explores our learning connections as a professional network of educators and researchers during the course enhancement process and presents how two pilot subjects at Deakin University embedded ePortfolio in two different disciplinary contexts: Information Technology and International Studies. These two ePortfolio pilots have since been integrated in the curriculum to assure learning outcomes in evidenced-based assessment, while facilitating career development learning and preparing learners for a rapidly changing future in the new knowledge economy.

\section{Course/Program Enhancement at Deakin}

Course enhancement opened a range of opportunities to approach curriculum design and development through a renewal of perspectives on learning, teaching, and assessment in all courses/programs at Deakin. It also enabled a multidisciplinary and transdisciplinary collaboration to learning design and a thorough critique of program learning outcomes using a design-thinking methodology. The focus on the program-wide approach invited all academics to plan, co-design, and implement an evidenced-based approach collaboratively rather than as individuals. This evidenced-based collective approach to program design, as a course team, presented particular opportunities to review how students demonstrate learning outcomes holistically through assessment across a program rather than focusing on a single unit or subject. Additionally, teaching teams invited a critical gaze on the quality and capacity of assessment design to provide evidence of program learning outcomes as the first point of reference for curriculum review. Importantly, teaching teams in higher education settings vary considerably in collaborative experiences of program renewal (Benjamin, 2000; Pegg, 2014; Savage \& Pollard, 2014), and this may have some bearing on the extent of engagement with ePortfolios from a program perspective.

The course enhancement process included developing program coherence through course scoping and course (re)design. Course scoping consisted of the program being reviewed through a number of lenses, including an external review, learning analytics, and course and unit student and staff evaluations. Program needs were identified (school, faculty, professional accrediting bodies). 
These highlighted needs were then mapped for further exploration in the curriculum design (i.e., Australian Qualifications Framework ${ }^{4}$ requirements, research needs, etc.) through the development of co-designed new program learning outcomes in alignment with the Deakin graduate learning outcomes. Finally, the program learning outcomes were aligned to discipline-specific professional standards (if any) and discipline threshold learning outcomes in order to create and define a set of minimum standards to evidence learning.

This collaborative exploration of new course design further extended the LIVE the Future: Agenda $2020^{5}$ by structuring teaching and learning across all programs to align with the eight graduate learning outcomes. LIVE the Future: Agenda 2020, launched July 2012, encapsulates Deakin University's plan to bring the opportunities of the digital age into the real world of Learning, Ideas, Value, and Experience (LIVE). The course design included both cloud and located learning, teaching, and assessment with the learning design focusing on the alignment of assessment in each unit with learning outcomes, as well as resourcing the units and courses. Consequently, learning, teaching, and assessment center on the course rather than a collection of units or subjects.

\section{ePortfolio at Deakin}

Since 2014, Deakin's commitment to portfolio thinking and integrative learning has been shown by the continual uptake of ePortfolio into programs. Deakin's ongoing cultural change through learning and teaching and its focus on evidence in assessment for learning have provided impetus for faculty to further explore ePortfolio pedagogies. This shift in thinking at Deakin has allowed opportunities for exploration into the very nature of digital learning evidence for our students. To help support our understanding of ePortfolios in higher education, we consulted a range of practice-based research and evidence-based research on ePortfolios for learning and assessment to inform the learning design (Allen et al., 2012; Batson, 2013, 2014, 2015; Eynon et al., 2014; Hallam et al., 2008; Rhodes et al., 2014). In addition, we consulted research on ePortfolios for integrated learning (Huber \& Hutchings, 2004; Peet et al., 2011), career development learning (Coleman et al., 2012), and graduate employability (McKenzie et al., 2014) to support the development of Deakin's ePortfolio pedagogy in these programs. Deakin University's commitment to both evidence-based portfolio pedagogy and assessment as learning has continued, with digital credentials making a significant impact on evidenced portfolios and digital learning pathways (Deakin Hallmarks, 2016; Gibson et al., 2016).

Deakin University is working within a standards-based assessment framework (Boud \& Falchikov, 2006) and Constructively Aligned Learning Outcomes

4. A national system of qualifications encompassing all post-compulsory education.

5. Deakin University's teaching and learning strategic plan. 
curricula (Biggs \& Tang, 2011) to better ensure validity and reliability in assessment. Higher education institutions in Australia are accountable to the Higher Education Standards Framework (HESF) (2014), the Australian Qualification Framework (AQF), and the Tertiary Education Quality and Standards Agency (TEQSA), Australia's independent national regulator of the higher education sector. Standards-based assessment informs students of the criteria and performance standards used to judge their work. Standards-based assessment enables students to compare their learning evidence based on their achievement of the learning outcomes, which are designed to support the HESF and TEQSA criteria. Through alignment of learning outcomes and standards via engaging assessment, the course enhancement process at Deakin enabled a university-wide approach to develop clear and explicit processes for assessment as learning that support student experience in the cloud and on-location.

In this process, we reframed assessment as an opportunity for students to create evidence of their achievement of the Deakin graduate learning outcomes (see Figure 6.1) and demonstrate skills, experiences, and knowledge differently. As a result, all students are now encouraged to curate their learning evidence in an ePortfolio, whether it be an ePortfolio in CloudDeakin, a personal digital space, or a personally reflective professional social media ePortfolio created using Weebly, Wix, or LinkedIn.

\section{Deakin's Graduate Learning Outcomes}

* 1 Discipline knowledge

Outcomes and standards

(2) 2 Communication

Expectotions

(․) 3 Digital literacy

(i) 4 Critical thinking

? 5 Problem solving

(3) 6 Self-management

(23) 7 Teamwork

(1) 8 Global citizenship

1. Specify the course outcomes expected in discipline knowledge and generic skills as required in the Australian Qualifications Framework

2. Specify the standards required in those Course Learning Outcomes:

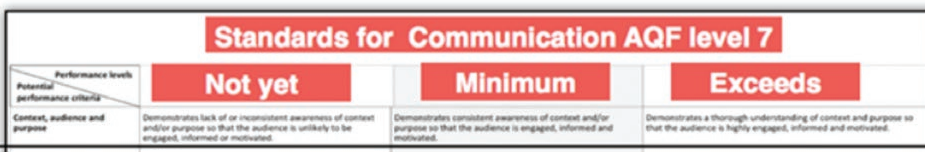

Figure 6.1. Deakin University's graduate learning outcomes framework. 
Deakin's curriculum framework has four key aspects. Programs at Deakin are designed for:

- Expectations: outcomes and standards clearly signal expectations aligned with the Australian Qualifications Framework.

- Evidence: assessment tasks enable compelling evidence of outcomes and standards, focusing on graduate employability.

- Experience: inspiring educators offer personal, interactive, and engaging learning experiences and resources in cloud and located learning.

- Enhancement: emphasis is on the systematic evidence-based enhancement of courses.

Figure 6.1 demonstrates our key graduate learning outcomes (Oliver, 2014) and the ways in which these outcomes are constructed to reflect the high standards put forward in the Australian Qualifications Framework. ePortfolios are a major contributor to Deakin's ability to demonstrate student achievement of these outcomes.

\section{Research Questions}

As a part of the course enhancement process, the following research questions guided the qualitative, case study-driven research presented in this chapter:

- What does an ePortfolio for learning, assessment, and careers look like at Deakin?

- What is the value of an ePortfolio in our context for evidencing graduate learning outcomes? (see Figure 6.2)

Our case study into ePortfolio practice focused on students' ePortfolios in the Bachelor of Information Technology (BIT) and the Bachelor of International Studies (BIS).

\section{Research Inquiry}

To ensure the research critically engaged with what we knew about ePortfolios for learning, assessment, and careers, our approach considered metacognition (Wozniak \& Zagal, 2013), personalized learning (Batson, 2015), and self-regulated learning (Pintrich et al., 200o) that were deemed necessary components of our program. To identify the value of ePortfolios at Deakin, we developed our own experiential and problem-based learning opportunity through a focus in the BIT and BIS programs. With support from the university via the course enhancement process, we co-designed and developed ePortfolios for learning, assessment, and careers through an iterative design process. The Stanford School design thinking methodology, as well as the stages set out by Morris and Warman (2015), best supported the learning design process, as well as the approach of this study. Design 
thinking has worked well in Deakin's interdisciplinary and cross-disciplinary approach to ePortfolio learning design and was key to the shared successes described in the case studies. We followed this five-step process to support our research:

1. Empathize: Through discussion, reflection, observation, and investigation of the terrain of ePortfolios in higher education, our research was based in the fields of ePortfolios for career development and employability, personalized learning, and evidenced-based learning through assessment.

2. Define: Through examination of a range of views and perspectives (POV) as a multidisciplinary team, we developed the learning design requirements to support a range of learners and learning needs.

3. Ideate: An iterative phase for learning design and research asks that all stakeholders bring their ideas to the table to be sorted through and reflected upon to collectively decide on the perceived needs for learning. In this instance, the collaborative ideation phase led to an iterative design and development of a range of prototype templates for the Bachelor of IT

4. Prototype: In a design-thinking process (Naiman, 2016), the prototyping requires an iterative implementation followed by a redesign to take into account evaluation and new ideation based on evidence from learning analytics (see Castaño \& Nova, this collection). In this instance, it led to a new research question and focus on developing clearer pathways for ePortfolios as we reviewed the student feedback (from an ethics-approved research project) based on value to learning.

5. Test: Through our graduates, we examined what ePortfolios would look like collaboratively as a course in the BIS and BIT. This feedback and evaluation of the test led the team back to ideation and prototyping a new program design.
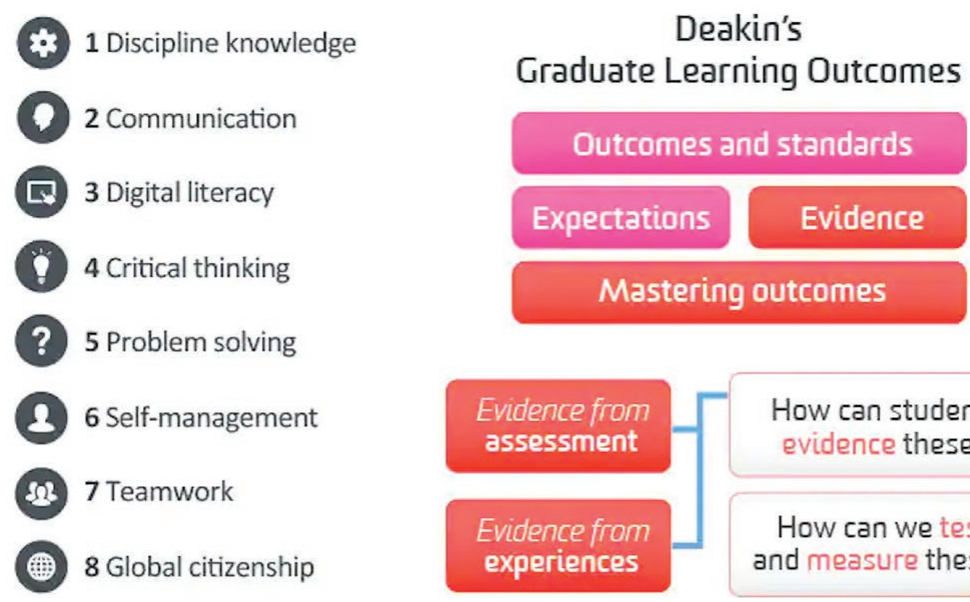

\section{Outcomes and standards}

\section{Expectations \\ Evidence}

Mastering outcomes

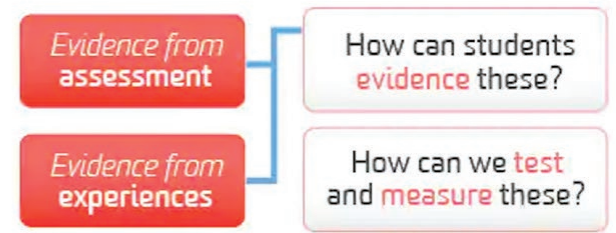

Figure 6.2. Deakin's underpinning curriculum model. 
Our cyclic and design-thinking approach to curriculum development was supported by shared reflective practice that opened up new opportunities for learning design and a re-visioning of the research inquiry to suit individual and collaborative reflections. To address the research questions, we focused on a number of areas. First, we explored the language of ePortfolios from local, national, and international perspectives to look for overlaps, connections, contextual differences, and synergies. Secondly, we examined the different contexts and purposes of an ePortfolio (process, product, showcase, career/cv, assessment, learning, and journal). Thirdly, we focused on the varied pedagogy and technology needs in a range of sites. Over time it became apparent how discipline-specific (local) issues impacted not only the ways in which both faculty and students adopt ePortfolio, but also how they utilize ePortfolio for evidencing claims to learning.

To develop the local, national, and international language of ePortfolio, we made significant changes to learning design and assessment. These changes ensured appropriate and effective evidence mapping of student skills to learning outcomes could be reported in ePortfolios. Not only did students need to embrace the discipline-specific/local language of ePortfolio, they also needed to consider how to successfully reflect and build skills from a global perspective as graduates. The teaching and research team involved in this study agreed upon the importance of reflection towards successful ePortfolio creation (in any context); however, development of reflection within each discipline was a variable. Each discipline grappled with what reflection is, the action of curation as reflection, the reflection of intent, and whether reflection is an artifact (a piece of evidence) or something else altogether.

The following case studies highlight and explore examples from the BIT and BIS programs and demonstrate the local language of ePortfolio.

\section{Case Study I: Bachelor of Information Technology (BIT)}

The BIT is a technically-oriented computing discipline with specialized majors such as Games Design and Development and Security, which are offered both online and on campus. At Deakin University, we introduced an ePortfolio in the BIT in 2012. At this time, the School of Information Technology regarded development of a professional portfolio (physical or electronic) as a useful tool to enhance students' career preparation, thus a campus-wide initiative to introduce ePortfolios began. Endeavors to support students in ePortfolio creation continue; however, it was from the early investigations into ePortfolio (in 2012) that the true nature and use of an ePortfolio in IT became apparent. The following case study summarizes the experiences of a student from IT in creating an ePortfolio and how it can be used as a careers and assessment activity.

Games Design and Development (GDD) is one particular IT discipline that requires curation and dissemination of an ePortfolio. As a competitive employment, the GDD environment requires that educational providers strongly sup- 
port students' efforts to collate and present their skills and abilities in ePortfolios. Therefore, Deakin supports students to ensure career readiness and high levels of self-efficacy so they can negotiate the employment market. We rolled out an ePortfolio assessment model in the GDD classes at Deakin in 2012, with one class (called "Audio and Visual Game Elements") in particular focusing on the skills required for successful ePortfolio construction. Instructors required students to construct an ePortfolio based on the audio and visual game components developed during the teaching period. Progressive and final folio submissions as well as an oral presentation to demonstrate the ePortfolio work constituted the ePortfolio assessment model. The assessment epitomized a student-centered approach via progressive submission of ePortfolio assets with formative feedback and guidance provided throughout the teaching period. Progressive ePortfolio construction enabled a reciprocal, one-on-one feedback and discussion activity that prompted students to critically engage with gaps in their ePortfolios to improve future submissions. Figure 6.3 is an example of a final ePortfolio submission from the student in the class Audio and Visual Game Elements.

A critical part of the ePortfolio construction process in Audio and Visual Game Elements was the ability to reflect upon progress and act upon reflection to improve outcomes. Reflection allows students to refine their ePortfolio focus and requisite skills to achieve their goals. To assist the students in the class Audio and Visual Game Elements with the process of reflection, institutional stakeholders developed a set of resources in partnership with the student cohort.

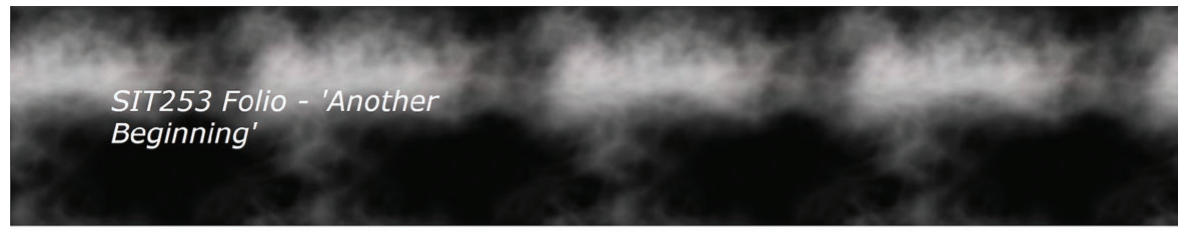

Final assets

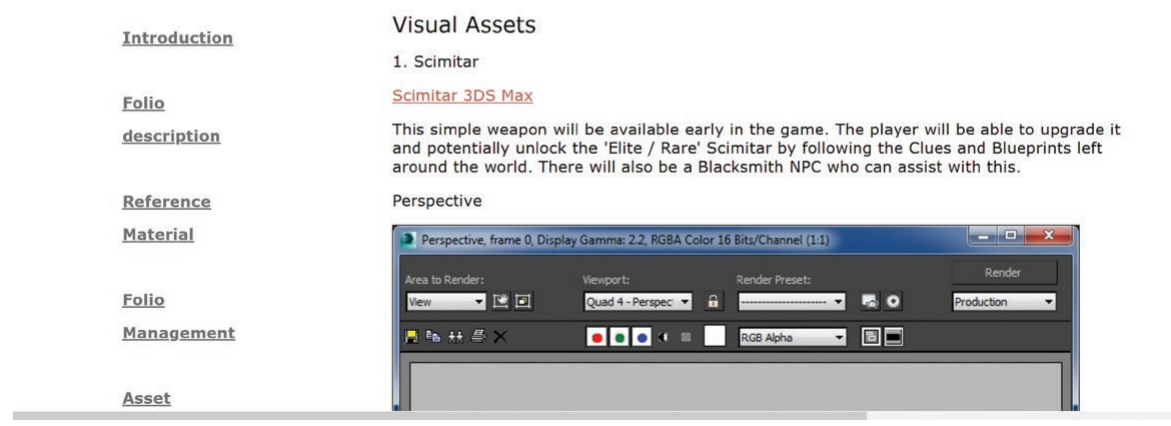

Figure 6.3. A student ePortfolio example from Games Design and Development (published with permission). 
The change to ePortfolio pedagogy as achieved in Audio and Visual Games Elements was new for many IT students, yet they highly appreciated how the ePortfolio provided individualized learning experiences. For example, one student commented in their end of class review: "I really liked the way the work was planned out, showing weekly progress was possibly the best way of me keeping up to date and getting the best out of my portfolio." In addition to such student comments, the grades show that student outcomes from the course since refinement have been higher, with High Distinction (HD) and Distinction (D) grades rising from $13 \%$ and $20 \%$ in 2011 to $20 \%$ and $28 \%$ respectively in 2012 . The outcomes from using ePortfolios for assessment in Audio and Visual Game Elements proved positive. Students valued the institutional commitment to ePortfolio creation, as it facilitated their personalized learning and supported them in the development of relevant skills. In addition, the revised approach to assessment in Audio and Visual Game Elements reflected the requirements of the GDD industry (as confirmed by the School of IT industry advisory board), as it equipped students with a platform to demonstrate their skills beyond the final class grade. Furthermore, the approach allowed for greater alignment to unit (class) and program learning outcomes.

Other ePortfolio explorations have occurred in the School of IT in an effort to assist students in developing skills for successful curation. However, this research has uncovered issues in the ways in which ePortfolio pedagogy should be employed for students in IT, as they find the concept of creating an ePortfolio for their future career as secondary to achieving good grades. The value of ePortfolio as a tool to assist future employability is lost without clear articulation of assessment and activities that focus on ePortfolio construction (see Dellinger \& Hanger, this collection). It is difficult to teach students the value of curating, reflecting, discussing, and reporting on learning through ePortfolios. Developing motivation in ePortfolio pedagogy is not limited to students; instructors, too, are often unaware of the extent to which using an ePortfolio requires significant modifications to their pedagogy. Thus the use of ePortfolios in the School of IT largely remains a class-based approach, pushed forward by faculty who embrace the value of students curating personal learning outcomes. Future activities in the School of IT to change practice and embrace ePortfolio pedagogy across the program include implementation of extensive online resources that assist students to develop their own ePortfolio for employability.

\section{Case Study 2: Bachelor of International Studies (BIS)}

The Bachelor of International Studies (BIS) is an interdisciplinary humanities degree program with a compulsory international experience requirement and an explicit commitment to facilitating the development of skills and capabilities required for working in international environments. ${ }^{6}$ Launched in 2009, it has

6. The BIS degree structure is built around six core courses, an eight-credit major sequence (selected from a choice of nine), and at least two credits of international experience. 
since gone through three iterations to reach its current structure.

Implementation of an ePortfolio in the BIS had been attempted prior to Deakin's course enhancement process via one of the core units, but was not successful. Nonetheless, interactions with students undertaking internships along with discussions with student representatives on the program Advisory Board indicated that there was a clear need to help students articulate and evidence the skills they were gaining over the course of the program. Almost all of them described their international experiences as "the best thing I've done in my studies" but even in the case of strong students, few were able to explicitly articulate how these experiences linked to their classroom studies and overall development.

Through the Course Enhancement process, the use of an ePortfolio became evident as a way for students to reflect on their learning both from their international experiences and the duration of the whole program, thus enabling them to better articulate the knowledge and skills they had developed.

In order to better understand what a BIS Graduate ePortfolio would look like, two students were recruited to build a graduate ePortfolio and provide feedback on their experience. Both students were completing the final 23 units of their program and undertook the project as a credit-bearing internship. While it was initially tempting for the supervisors to try and give prescriptive instructions about technological and content requirements, the students instead received a brief that set parameters for the ePortfolio, but left them to work out the details themselves. The students were asked to:

- Develop and compile an ePortfolio on a platform of their choice using audio-visual elements.

- Report Bachelor of International Studies Program Learning Outcomes and Deakin Graduate Learning Outcomes via a development report.

- Reflect on their learning experience with support from evidence.

- Commit approximately 150 hours (equivalent to 20 working days) to ePortfolio development (writing, making notes on what worked/didn't work, what questions arose while they were working on the project), plus approximately 150 hours consulting with their supervisor, conducting research, and completing assessment tasks.

The two ePortfolios produced for the BIS were very different. One was outward-looking and focused on showcasing the author to an external audience such as potential employers, while the other was more inward-looking and explicitly reflective, centering on how each Deakin Graduate Learning Outcome could be evidenced.

Encouragingly, both students felt that the process of creating an ePortfolio proved beneficial for them. As they commented:

Over the past three months I have researched, analysed and self-reflected upon many different aspects of my degree and 
delved into the world of ePortfolios and their benefits to one's education. The use of ePortfolios is a beneficial tool for educational purposes in order to self-reflect upon many different aspects of your degree and academic achievements. It allows you to creatively present how those achievements have influenced you as a graduate and a professional. ... Reflecting upon all the incidents when I have achieved these Outcomes [sic] has been one of the most influential academic, professional and personal achievement of mine, as previously stated, creating a [sic] ePortfolio of this magnitude allows me to take enormous pride in my achievements and academic pursuits over the past three years. (Emily)

An ePortfolio is particularly useful as a tool for reflection on learning. It creates an environment where a student remains engaged with a body of work during an entire program of study rather than consigning first year work to a box in the back of a cupboard, for example. (Matthew)

While only a very small-scale project, these conclusions confirmed that the process of creating an ePortfolio has significant potential for scaffolding students' understanding and articulation of the meta-narrative of their learning pathways by encouraging them to shift their focus from individual units towards making connections between units and experiences both inside and outside the classroom and institution (see Terry \& Whillock, this collection).

However, the students' reports on their experiences of creating ePortfolios in response to the brief provided confirmed that they had encountered similar issues in developing their ePortfolios. Four issues in particular stood out, as outlined below, along with our interpretation of their importance: 1) What was the point of doing this?, 2) Issues with digital platform and format, 3) Understanding evidence, 4) Community of ePortfolio.

\section{What's the Point of Doing This?}

Especially early on, even though they understood the brief and output, it was evident that the students struggled to link the process of ePortfolio creation and curation to the development of metacognitive skills and the capacity for reflective narration. Rather, they identified how the process could assist them with demonstrating specific skills or learning outcomes such as digital literacy or global citizenship, or could help them use the final ePortfolio in a particular way, such as a showcase for potential employers. Helping them see the "bigger picture" of their program involved reframing the students' experience of being university students as one of telling a retrospective story about their personal and professional growth over several years, as a teaching assistant's email (sent February 18, 2015) 
to Emily illustrates: “. . a ePortfolio at its most basic is a multimodal narrative. A story retold and constructed by you in a curated space" (Teaching Assistance comment, 2015).

Over the duration of the experiments in BIS, the narrative potential of ePortfolios became far more evident to both students. However, it is not a process that can be left to chance and points to the fact that ePortfolio thinking needs to be explicitly presented and discussed with students when they begin creating their ePortfolio. Having an explicit discussion with students about the process and purpose of creating ePortfolios is especially important as it often contrasts starkly with students' preexisting understandings of learning as being primarily time limited (that is, occurring only over the duration of a specific unit) and measured by outcomes. Shifting to emphasize process and the culmination of knowledge and experience involves "unlearning" in a similar way to that required by problem-based learning (Wilkinson, 2013). Scaffolding this process effectively is crucial as one is in effect removing the old scaffolding (dependent students for whom learning is equated with success in assessment), leaving students feeling unsupported, which is likely to reduce their capacity to transition to viewing themselves as independent and lifelong learners, at least in the shorter term.

This metaphor has become an important theme in our practice particularly in the BIS. In The Postmodern Condition: A Report on Knowledge, Jean-François Lyotard (1979) refers to narrative knowledge and the role of storytelling as narrative. Translated to the BIS, students need to be able to explain what they have studied. As an interdisciplinary program, students select one major from a choice of nine (International Relations; Politics and Policy Studies; Middle East Studies; Anthropology; Language and Culture Studies; Arabic; Indonesian; Chinese; or Spanish), choose up to 10 electives, and are required to have at least one international experience. Beyond the six core courses, the program is highly personalized. While in many ways choice of subjects to study is a positive element, graduates must be able to narrate their course selections and how their program developed. Employers need to understand the student's journey within the BIS, as each journey is not standardized as with other degree programs. Lyotard's (1979) concept is taken a step further in that the BIS aims to facilitate the creation of reflective storytellers who can explain not only what they did, but also why they made a particular choice, what they gained from that decision, and the applicability of their learning to other contexts. While ideally this construction of narrative knowledge would be an ongoing process over the program of a student's studies, in practice Søren Kierkegaard's maxim that life must be lived forward but can only be understood backwards more closely reflects the experience of most students. As such, we wanted to explore how ePortfolios could be used to support the sense-making and narrative processes for BIS students at the end of their programs by providing an opportunity to look back at their studies and achievements and understand how they all link together. 


\section{Platforms and Format}

While platform selection must be informed by the pedagogy, disciplinary context, and the audience who will engage with the ePortfolio as a product (see Richardson et al., this collection), the choice of platform is also important for student ownership and personalization. Authenticity is key component of ePortfolio pedagogy, and one that is often overlooked in assessment and learning design. We concluded that open digital platforms more often permit external engagement and provide authenticity and usefulness to the ePortfolio by giving students "real world" experience. In contrast, we viewed the internal Deakin ePortfolio as clunky and limited in terms of audience and learning community.

At the same time, not all students will be familiar with suitable platforms from the outset, so if instructors permit student choice, they must factor in time for students to explore and experiment with different platforms. Moreover, the use of open platforms increases the importance of discussing aspects of digital literacy such as copyright and protecting intellectual property rights, as well as reputational management (see Garriott, this collection). While initially this may seem like an additional burden, integration of such discussions links well to ePortfolio thinking and promotes reflection, while providing a way to scaffold the ePortfolio creation process in the early stages.

\section{What Evidence Is There?}

Asking even the most engaged students to recall everything that they did over a three- to five-year period is a tall order. The task becomes doubly challenging when students are expected to evidence program and graduate learning outcomes that are constantly changing, even over the duration of a standard threeyear program. Retrofitting learning outcomes is not desirable and risks reducing student buy-in and confidence. Developing an ePortfolio can facilitate student thinking about how to evidence each Deakin Graduate Learning Outcome effectively by giving them an initial opportunity to conduct a "stock take" of potential artifacts and sources of evidence. The need for students to link curricular and extracurricular activities in their ePortfolio evidence came to light as a second issue that demanded our attention. For example, despite being an on-campus student, Emily's evidencing of how she met the Teamwork Deakin Graduate Learning Outcome drew not only on her engagement in courses and successful completion of group assessment tasks, but also volunteering experiences that she had undertaken independently. In addition to describing the evidence, she reflected on the progress that she had made over the duration of her studies, commenting that "Understanding how I can contribute to a team environment is something I value greatly and have developed further over the past three years and strive to further develop throughout my Honours year" (Emily http://emilyebbott.wixsite. com/deakineportfolio2015/collaborative). 
Matthew's discussion of Global Citizenship, the final of the eight Deakin Graduate Learning Outcomes and paramount for the BIS, took the combining of curricular and extracurricular a step further. Using the ePortfolio to produce a new artifact and reflection in one (see Figure 6.4), he demonstrated his understanding of global citizenship through a photo essay that illustrated how residents of a New York neighborhood "enact their local and global citizenship just by their very existence within this geographical space." (Matthew, Figure 6.4)

The photo below depicts a storefront window advertising services to immigrants mainly from the Bengali community who need connections to their country of origin. The services advertised include airline tickets, international money transfers, and mobile phones and their associated services. These are valuable services for immigrants who have yet to establish themselves in their new country of residence and may not have traditional bank accounts or personal infrastructure.

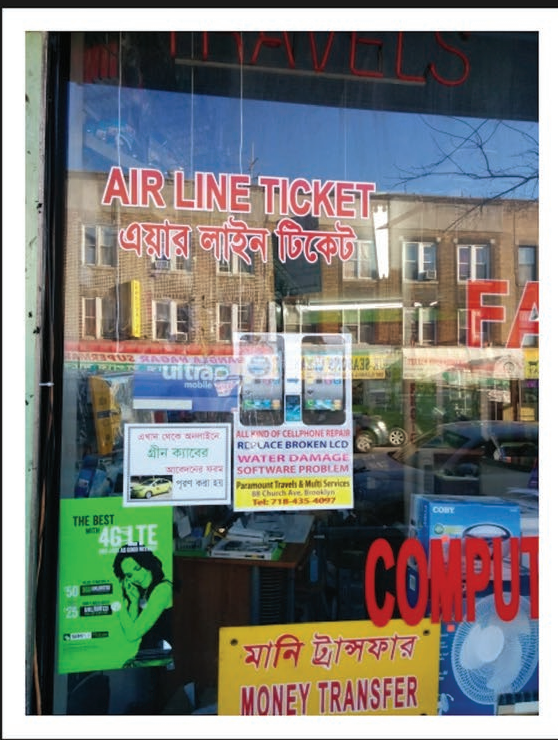

Posters advertising services to local residents, especially immigrants wanting to remain connected to their country of origin. Photo: Matthew Hall

Figure 6.4. Excerpt from Matthew's photo essay about global citizenship (https://matthewhallportfolio.wordpress.com/global-citizenship/) 
In addition to highlighting the need to bridge the curricular/extra-curricular divide, constructing an ePortfolio demonstrated the importance of seeing the program as a whole story with multiple interwoven, connected threads and moments. It began to break down the distinction between learning undertaken in a formal learning environment (whether in a classroom or online), and learning in other settings via participation in different activities and communities: an important "aha moment" in reframing students' perceptions of the value and benefit of their university experiences. Finally, it confirmed the idea that reflection can serve as an artifact in its own right and hence a potential solution to any lack of evidence that has the additional benefit of demonstrating reflection as an iterative and ongoing practice.

\section{Community, Collaboration and Evolution}

The temptation is to see ePortfolios as highly individual and as individualized projects that primarily showcase the student or graduate. However, with the shift to focus on process and promotion of a new model of learning, the importance of collaboration and opportunities for discussion became very evident. Both students noted the challenge of feeling isolated, although Emily's perception was perhaps more acute due to having completed the majority of her program on campus and starting work on her ePortfolio while still travelling in Europe.

During the beginning of the project I felt slightly separated from both my supervisor and my fellow student [Matthew]. This was rectified once I began to share ideas and worries with my fellow student. Once I returned home I spoke to my supervisor and the level of information was greatly appreciated because there is only so much one can convey via email through no fault of either party. More integration and possible Skype sessions would have been beneficial although due to time difference made it quite difficult. (Emily)

We set up a Facebook group at the start of the project, which served as an effective forum for discussion and sharing of ideas. As a platform that all participants in the project already used, students avoided having to log into Deakin's Learning Management System. Matthew clearly explained the importance of the Facebook group in the concluding recommendations of his project report:

Students in many units are encouraged to use discussion groups on the Deakin cloud system to interact with cohort (sic), either informally or with particular relevance to unit topics. In some cases, this interaction is compulsory and forms part of assessment. In my experience, unless interaction in discussion forums are compulsory, use of that platform is non-existent. Using the 
Deakin experience as a guide, this "closed room" approach was counter-productive. The best communication tool is one that students already use-platforms like Facebook or Twitter. In units that adopted these platforms there was more engagement, communication and-importantly-sharing of ideas. Enabled by active social networks, communication bloomed. Content from an e-portfolio can be shared via these platforms (Facebook, Twitter), again expanding the opportunity for student communication, feedback, and reflection. This could be of particular use to off-campus students as experiential evidence suggests in-house platforms do not encourage wide nor regular participation. (Matthew)

Matthew's and Emily's greater awareness of the collaborative nature of learning that developed while creating their ePortfolios also led to a different understanding of outcomes, with a move away from the idea of learning as finite and merely about finding the "right" answer and towards embracing contingent and iterative knowledge production. Matthew illustrated this point with reference to a comment to students by David Carr that an online course he was teaching for the first time would be "exciting and sometimes very confusing" (Carr, 2014, Addendum, para. 1), reflecting that:

Part of Carr's point in this comment is that the digitalization of media and communication is inescapable, offers great opportunities, and is evolving. In an environment that therefore is evolving, perfection is difficult to achieve and trial, error, and failure can be considered an important part of a learning process. What is considered right today can be wrong tomorrow or, at least, improved upon later. While Carr was referencingperhaps even warning students about-his approach to teaching, the same philosophy can and should apply to learning. An e-portfolio which documents a student's evolution is the perfect tool, much like an analog scrapbook, to accompany that transition. It will not always be perfect-the finished article-but, like the student, it will or at least should evolve. (Matthew).

This final reflection got to key aims of introducing ePortfolios to the Bachelor of International Studies: to increase students' awareness of the contingency of knowledge and to promote an understanding of learning as an ongoing, dynamic, and interactive process, rather than being finite and static. In the process, both Emily and Matthew came to see the primary value of the ePortfolio as the process, rather than the product-a shift in thinking that reflects the importance of portfolio thinking and the willingness to challenge students' perceptions of the ePortfolio, which are often overly focused on how they can utilize the finished version. 


\section{Discussion}

Our case study has explored the complex ways in which ePortfolios can be used in a particular discipline, focusing on their particular contextual, purpose-driven learning design, and issues of audiences when curating. Embedded in a specific disciplinary focus, each case study demonstrates a certain "lens of learning" through particular language and cultural semantics. Similarly, the ways in which the instructor(s) articulate and explicitly demonstrate the aims of an ePortfolio and its outcomes to students highlight the significance of ePortfolio pedagogy. Both the learner's identity development and their growing knowledge of the content become evident in their integration of multimodal media selections as well as the curatorial decisions they make in constructing a presentation for a particular audience. The interaction of artifacts and evidence as a curated page creates a narrative that represents the learner in the discipline/profession and reflects the learner's representation of self. The viewer of the ePortfolio not only sees the transformative evidence curated by the learner but also how the learner has designed their learning journey. Again, these outcomes depend on the purpose and audience of the ePortfolio and differ from discipline to discipline. Overall outcomes from the case study include:

- Reflection: The nature of reflection in each discipline differs. The examples allowed exploration of exactly what constitutes reflection within each discipline, as well as mechanisms for how students build and articulate reflection. This "skill" takes time to build, yet reflection represents an important layer in the assessment process. The way we view reflection either as a lower-case $\mathrm{r}$ or an upper-case $\mathrm{R}$ has many disciplinary-specific contextual differences that influence the language and style. When we teach reflection and/or Reflection, we are also using different disciplinary models and need to be aware of this difference by making it explicit in our teaching and research outcomes. We found that students could identify the relationship between the evidence and reflective pieces through constructed reflections on evidence or "in action" (Schön, 1983, ix) through the curatorial decisions they made as they designed the pages or presentations.

- Evidence: We view evidence through a range of perspectives that depend on a number of contexts, from evidence of learning, evidence of a skill, experience, or as a whole program. We understand evidence to have many meanings and connotations when we talk about ePortfolios, for example: a curated ePortfolio of evidence; an ePortfolio that contains artifacts as evidence; a curated ePortfolio that uses evidence to support claims through reflection.

- Materiality: An artist or designer discusses material practice and materiality to present his/her intent through the media. This perspective has implications for the way we use it in ePortfolios; we could be referring to the multimodal media explored throughout the ePortfolio composition, the actual composition as a whole, or the way materials are used to lead the 
viewer from one artifact to another and the impact or impression of that artifact. For instance, how the I-Am statement language in the BIS is used by the artist or designer impacts the way an audience views a photograph to the way they read the page structure. The materiality can shape our lenses as viewers and lead the reader through the constructed narrative.

- Standards: We view standards in each of our educational contexts, nationally and internationally, through a range of perspectives. We use standards to define achievement and evidence of learning outcomes, have our own standards as teachers and educators, and have standards that we must adhere to in our institutions. One set of standards becomes confused with others when we talk about them in relation to ePortfolios.

\section{Conclusion}

The course enhancement process at Deakin has enabled us to explore the value of ePortfolios and present the ways in which we use ePortfolio for learning, assessment, and careers. It also opened our practice to seeing the role that explicit standards had in the learning design of a course. Other educators considering ePortfolio pedagogy across programs must carefully consider discipline-specific issues particularly when determining the nature of reflection, evidence, materiality, and standards. Context issues impact the way in which students curate their ePortfolios. The implementation of technical proficiency for both staff and students takes time as do developing appropriate pedagogical understandings of the tools and the ability to critically reflect and select work for assessment. Overall, as educative spaces, ePortfolios enable both a self-directed and personalized approach to learning that promotes lifelong and life-wide capabilities for reflection and collection of work samples for a range of audiences. ePortfolios also offer the opportunity to present competing or evolving standards enabling both students and educators to negotiate their relevance while validating the course outcomes. As learners develop the appropriate skills to self-regulate their learning and become responsible for their learning outside of the formal learning environment, ePortfolios offer a space to engage both individually and collaboratively for a purpose that is both personalized and assessable. Educators seeking to develop personalized learning spaces or authentic learning environments in their assessment will find that ePortfolios can enable this transition.

\section{References}

Allen, B., Caple, H., Coleman, K., \& Nguyen, T. (2012, November 26). Creativity in practice: Social media in higher education [Conference paper]. Ascilite 2012 Future Challenges, Sustainable Futures. Wellington, New Zealand.

Batson, T. (2013, January 16). The taming of the MOOC-With ePortfolio evidence, Campus Technology Digital Magazine. https://web.archive.org/ 
web/20130318015052/http://campustechnology.com/articles/2013/o1/16/the-taming-of-the-mooc.aspx

Batson, T. (2014, April 23). Telling your story: Making sense of diverse learning experiences: Feature article in conversation with Mary Grush. Campus Technology Digital Magazine. https://campustechnology.com/Articles/2014/04/23/The-Narrative-Telling-Your-Story.aspx

Batson, T. (2015, April 19). Ontology of "ePortfolio" platform? Batson Blog. Association for Authentic, Experiential and Evidence-Based Learning. https://web.archive.org/web/20160406004742/http://www.aaeebl.org/blogpost/1008436/213232/ Ontology-of-ePortfolio

Benjamin, J. (2000). The scholarship of teaching in teams: What does it look like in practice? Higher Education Research and Development, 19, 191-204.

Biggs, J., \& Tang, C. (2011). Teaching for quality learning at university $\left(4^{\text {th }} \mathrm{ed}\right)$. McGraw-Hill; Open University Press.

Boud, D., \& Falchikov, N. (2006). Aligning assessment with long term learning. Assessment and Evaluation in Higher Education, 31, 399-413.

Carr, D. (2014, August 4). Press play: Making and distributing content in the present future we are living through. Medium, 4 August. https://medium.com/pressplay/press-play-4b26bed77b7d\#.aelsku8l8

Coleman, K., Cox, J., Das, M., Flood, A., Polly, P., Thai, T., \& Yang, J. L. (2012). Eportfolios in the sciences: The role of reflection as students build professional skills and career readiness. In M. Brown, M. Hartwell, \& T. Stewart (Eds.), Proceedings of Ascilite Wellington 2012: Future challenges, sustainable futures (pp. 219-222). Australian Society for Computers in Learning in Tertiary Education.

Deakin University. (2016) Deakin Hallmarks. http://www.deakin.edu.au/aboutdeakin/teaching-and-learning/deakin-hallmarks

Deakin University. (2015). Course Enhancement Guidelines 2015. https://www. deakin.edu.au/_data/assets/pdf_file/ooo3/321744/Deakin-Course-enhancement-guidelines-2015.pdf

Eynon, B., \& Gambino, L. (2015). The high impact ePortfolio practice: A catalyst for student, faculty and institutional learning. Stylus.

Eynon, B., Gambino, L. M., \& Török, J. (2014). What difference can ePortfolio make? A field report from the Connect to Learning project. International Journal of ePortfolio, 4, 95-114.

Gibson, D., Coleman, K., \& Irving, L. (2016). Learning journeys in higher education: Designing digital pathways for learning, motivation and assessment. In D. Ifenthaler, N. Bellin-Mularski, \& D. K. Mahin (Eds.), Foundation of digital badges and micro-credentials: Demonstrating and recognizing knowledge and competencies (pp. 115-138). Springer.

Hallam, G., Harper, W., Mccowan, C., Hauville, K., Mcallister, L., \& Creagh, T. (2009). ePortfolio use by university students in Australia: Informing excellence in policy and practice (Altc Project Final Report). Queensland University of Technology.

Huber, M. T., \& Hutchings, P. (2004). Integrative learning: Mapping the terrain: The academy in transition. Association of American Colleges and Universities. 
Lyotard, J. (1984). The postmodern condition: A report on knowledge (G. Bennington \& B. Massumi, Trans.). University of Minnesota Press. (Original work published 1979).

McKenzie, S. (2014). Incorporating career ePortfolios as a course wide learner tool. Proceedings Of The EPortfolio Australian Workshop. EPortfolios Australia.

McKenzie, S., Palmer, S., Coldwell-Neilson, J., \& Coleman, K. (2014, December 8-10). Understanding career aspirations of information technology students at Deakin University: A pilot study [Conference presentation]. IEEE International Conference on Teaching, Assessment, and Learning for Engineering 2014. Wellington, New Zealand.

Morris, H. E., \& Warman, G. (2015). Using design thinking in higher education. Educause Review, 12 Jan. 2015. https://er.educause.edu/articles/2015/1/using-design-thinking-in-higher-education

Naiman, L. (2016). Creativity at work: Design thinking as a strategy for innovation. http://oro.open.ac.uk/39207/1/curriculum_reform_final_19th_Dec.pdf

Oliver, B. (2013). Assuring graduate capabilities: Evidencing levels of achievement for graduate employability. https://ltr.edu.au/resources/Oliver_Report_2015.pdf

Oliver, B. (2014). Deakin University: Agenda 2020 curriculum framework. https:// www.deakin.edu.au/_data/assets/pdf_file/o013/300091/AGENDA-2020-curriculum-framework-DEC-2014.pdf

Oliver, B. (2015). Deakin curriculum framework, LIVE the future: Agenda 2020, http://www.deakin.edu.au/learning/deakin-curriculum-framework

Pegg, A. (2014). We think that's the future: Curriculum reform initiatives in higher education, Higher Education Academy. https://s3.eu-west-2.amazonaws.com/ assets.creode.advancehe-document-manager/documents/hea/private/curriculum_reform_final_19th_dec_1_1568037077.pdf

Pintrich, P. R., Walters, C., \& Baxter, G. P. (2000). Assessing metacognition and self-regulated learning. In G. Schraw \& J. C. Impara (Eds.), Issues in the measurement of metacognition (pp. 43-97). Buros Institute of Mental Measurement.

Polly, P., Thai, T., Flood, A., Coleman, K., Das, M., Yang, J. L., \& Cox, J. (2013, December 3). Enhancement of scientific research and communication skills using assessment and ePortfolio in a third year pathology course [Conference presentation]. $30^{\text {th }}$ Ascilite Conference. Sydney, Australia.

Peet, M., Lonn, S., Gurin, P., Boyer, K. P., Matney, M., Marra, T., Himbeault Taylor, S., \& Daley, A. (2011). Fostering integrative knowledge through ePortfolios. International Journal of ePortfolio, 1(1), 11-31.

Rhodes, T., Chen, H. L., Watson, C. E., \& Garrison, W. (2014). Editorial: A call for more rigorous ePortfolio research. International Journal of ePortfolio, 4(1), 1-5.

Savage, J., \& Pollard, V. (2014). Engaging academics in collegial online professional development during a course renewal process: Intent and reflection. In A. Kwan, E. Wong, T. Kwong, P. Lau, \& A. Goody (Eds.), Research and development in higher education: Higher education in a globalized world. (Vol. 37). (pp 274-283). Higher Education Research and Development Society of Australasia.

Schön, D. (1983). The reflective practitioner: How professionals think in action. Temple Smith. 
Wilkinson, C. (2013). More problem than solution? Managing the practical challenges of PBL course delivery. In K. S. Coleman \& A. Flood (Eds.), Disciplines: The lenses of learning (pp. 67-92). Common Ground Publishing LLC.

Wozniak, K., \& Zagal, J. (2013). Finding evidence of metacognition in an ePortfolio community: Beyond text, across new media. School of Continuing and Professional Studies Faculty Publications, 36. https://via.library.depaul.edu/snl-faculty-pubs/36 


\section{University Library}

\section{- M I I N E R VA \\ A gateway to Melbourne's research publications}

Minerva Access is the Institutional Repository of The University of Melbourne

Author/s:

Coleman, K;McKenzie, S; Wilkinson, C

Title:

Developing Learning-Centered Approaches across the Discipline: Implementing Curated ePortfolios in Information Technology and International Studies

Date:

2021-05

Citation:

Coleman, K., McKenzie, S. \& Wilkinson, C. (2021). Developing Learning-Centered Approaches across the Discipline: Implementing Curated ePortfolios in Information Technology and International Studies. Dellinger, MA (Ed.). Hart, DA (Ed.). ePortfolios@edu: What We Know, What We Don't Know, and Everything In-Between, (1), pp.103-124. The WAC Clearinghouse; University Press of Colorado.

Persistent Link:

http://hdl.handle.net/11343/280160 